Appl. Ent. Zool. 7 (2) : 52-60 (1972)

\title{
Biology of Hyphantria cunea DRURY (Lepidoptera : Arctiidae) in Japan \\ XIII. Temperature Drop as a Time Cue for Adult Eclosion
}

\author{
Yoshio HiraI \\ Institute of Forest Zoology, Faculty of Agriculture, University of Tokyo, 113 Japan
}

(Received November 22, 1971)

\begin{abstract}
The role of temperature as a time cue for the eclosion of adult Hyphantria cunea DRURY and its interaction with photoperiodic stimulus were experimentally analyzed. Experiments with various combinations of thermoperiods and photoperiods indicated that the timing of eclosion was determined not only by the light-off stimulus, but also was strongly affected by the stimulus of a drop in temperature. Further experiments showed that a change in temperature as well as in light, can act as a "phasing" factor in the endogenous circadian periodicity. However, the peak of eclosion occurred before the stimulus by a drop in temperature, while it occurred after the stimulus by light-off. This suggested the difference in the mode of action between these two stimuli. When animals were experimentally forced to make a choice between these two stimuli, it was revealed that a drop in temperature had stronger effect as the time cue for adult eclosion than light-off. Eclosion of the overwintered generation before dusk seemed to be caused by the drop in temperature at this season.
\end{abstract}

\section{INTRODUGTION}

The adult eclosion of Hyphantria cunea DRURY is assumed to be determined primarily by the change from light to dark. The rhythm of adult eclosion had persisted under continuous darkness and therefore was apparently endogeneous, and in addition to the light-off stimulus, the role of temperature in the timing of adult eclosion was suggested (Hirar, 1969). The present work was carried out to confirm experimentally the role of temperature and its interaction with photoperiodic stimulus as the time cue for adult eclosion.

\section{MATERIALS AND METHODS}

The eggs and larvae used in the experiments were collected from cherry trees in the suburban streets and Tokyo University Forest Experiment Station at Tanashi, Tokyo. Larvae were reared with fresh leaves of cherry as diet in outdoor wire-netted cages. After pupation the pupae were transferred into dark chambers under conditions of controlled temperature and photoperiods. Temperature was kept at 26士 $0.25^{\circ} \mathrm{C}$ in one of the chambers and at $19 \pm 0.25^{\circ} \mathrm{C}$ in another throughout the experiments. For obtaining temperature cycles, the plastic case containing pupae was transferred, carefully packed in a light-proof tin-box, from one chamber to another at the designated intervals. In this transfer mechanical disturabnce was carefully avoided. The pupae were subjected to the experimental conditions for about ten days throughout the pupal period until emergence. Counting of emerging moths was made as 
described in a previous paper.

\section{EFFECTS OF TEMPERATURE}

As stated in a previous paper (HIRAI, 1969), the field data suggested that temperature conditions, especially a drop in temperature, exerts some effect on the timing of adult eclosion. The first series of experiments was carried out to confirm the effect of a drop in temperature on adult eclosion. A group of pupae was subjected to, eqully
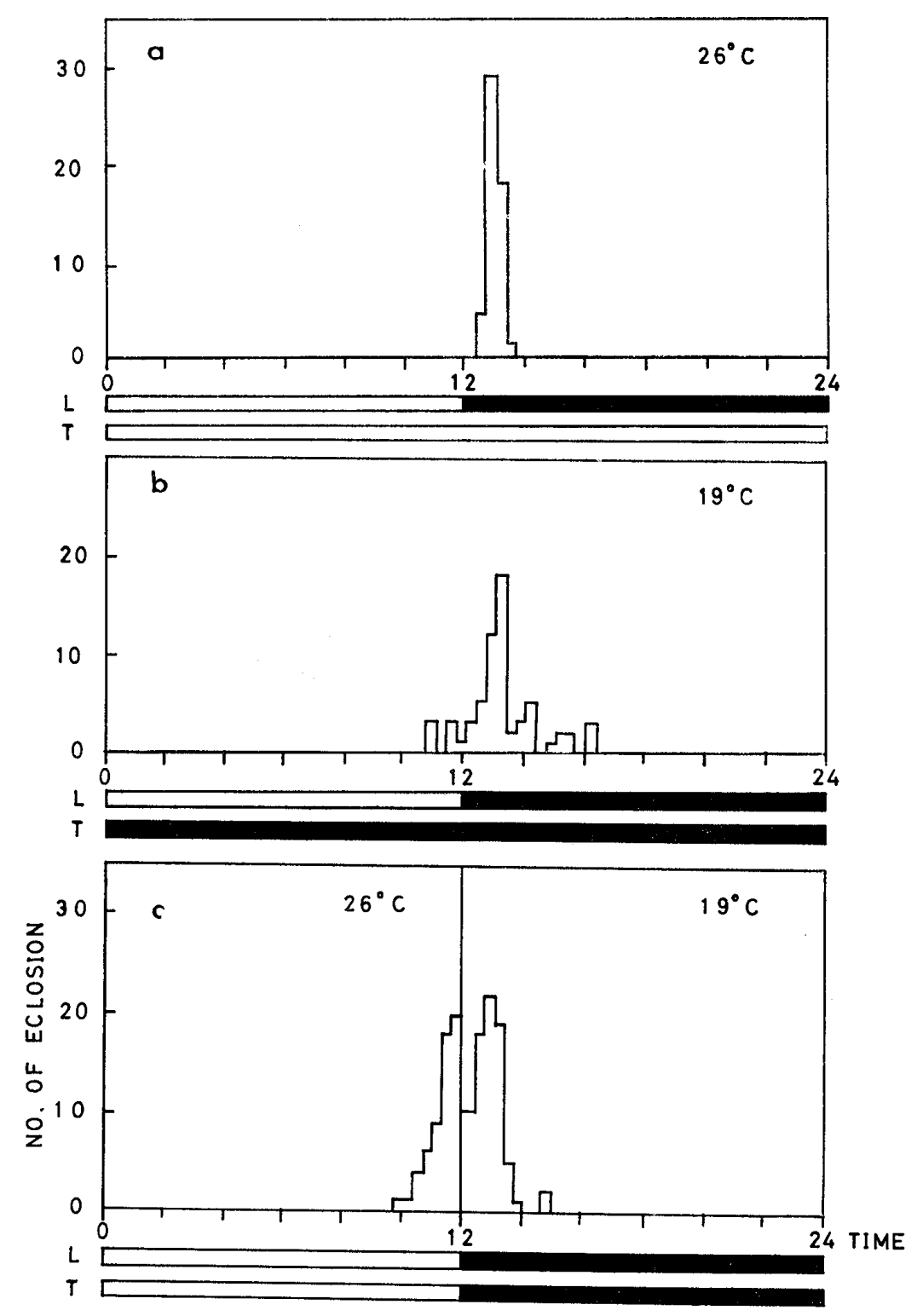

Fig. 1. Patterns of adult eclosion in $H$. cunea in a photoperiod of $12 \mathrm{~L} 12 \mathrm{D}$ at various temperatures: $26^{\circ} \mathrm{C}$ (constant) (a), $19^{\circ} \mathrm{C}$ (constant) (b), and a cycle of $26^{\circ} \mathrm{C}$ and $19^{\circ} \mathrm{C} \mathrm{(c).} \mathrm{The}$ $\operatorname{bar}(\mathrm{s})$ at the bottom of each figure show the regimes of light $(\mathrm{L})$ or temperature $(\mathrm{T})$. The open portion indicates light or high-temperature $\left(26^{\circ} \mathrm{C}\right)$ phase and the black portion shows dark or low temperature $\left(19^{\circ} \mathrm{C}\right)$ one. This expression applies to all the following figures. 
under a photoperiod of $12 \mathrm{hr}$ of light and $12 \mathrm{hr}$ of darkness (12L12D), three different temperature conditions: group $1-26^{\circ} \mathrm{C}$ (constant), group $2-19^{\circ} \mathrm{C}$ (constant), and group 3-a cycle of $12 \mathrm{hr}$ of $26^{\circ} \mathrm{C}$ and $12 \mathrm{hr}$ of $19^{\circ} \mathrm{C}$. In group 3, the change of temperature from $26^{\circ} \mathrm{C}$ to $19^{\circ} \mathrm{C}$ was made at the time of light off. As shown in Fig. 1 a, $\mathrm{b}$, in either of group 1 or 2 , the peak of eclosion occurred 1 hour after light off. In group 3, however, nearly half of the individuals emerged after light off and the rest did so before light off (Fig. 1-c). These results indicate that the drop in temperature exerts a strong modifying effect on the timing of eclosion, inducing earlier eclosion. There is a possibility that a drop in temperature might even act as a time cue or signal for eclosion.

\section{DROP IN TEMPERATURE AS A TIME GUE}

The possibility mentioned above was confirmed by the experiments described below. A group of pupae was kept in a thermoperiod of $12 \mathrm{hr}$ at $26^{\circ} \mathrm{C}$ and $12 \mathrm{hr}$ at $19^{\circ} \mathrm{C}$ in continuous darkness. Namely, they were subjected to a $7^{\circ} \mathrm{C}$ rise and drop in temperature. As shown in Fig. 2-a, a definite peak of adult eclosion was observed about
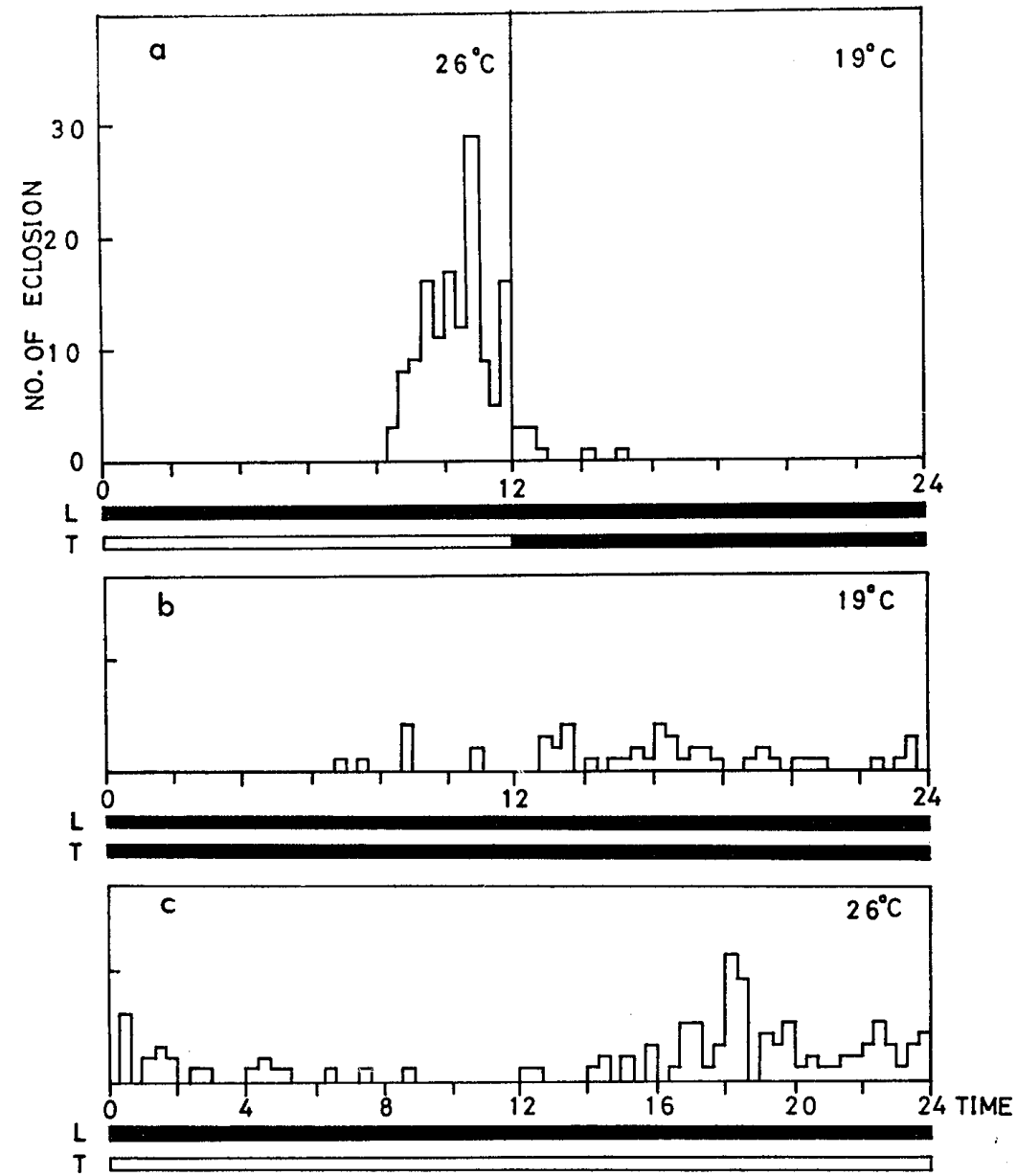

Fig. 2. Effect of drop in temperature in continuous darkness on the adult eclosion of $H$. cunea. a: $26^{\circ} \mathrm{C}$ constant, b: $19^{\circ} \mathrm{C}$ constant, c: a cycle of $26^{\circ} \mathrm{C}$ and $19^{\circ} \mathrm{C}$. 


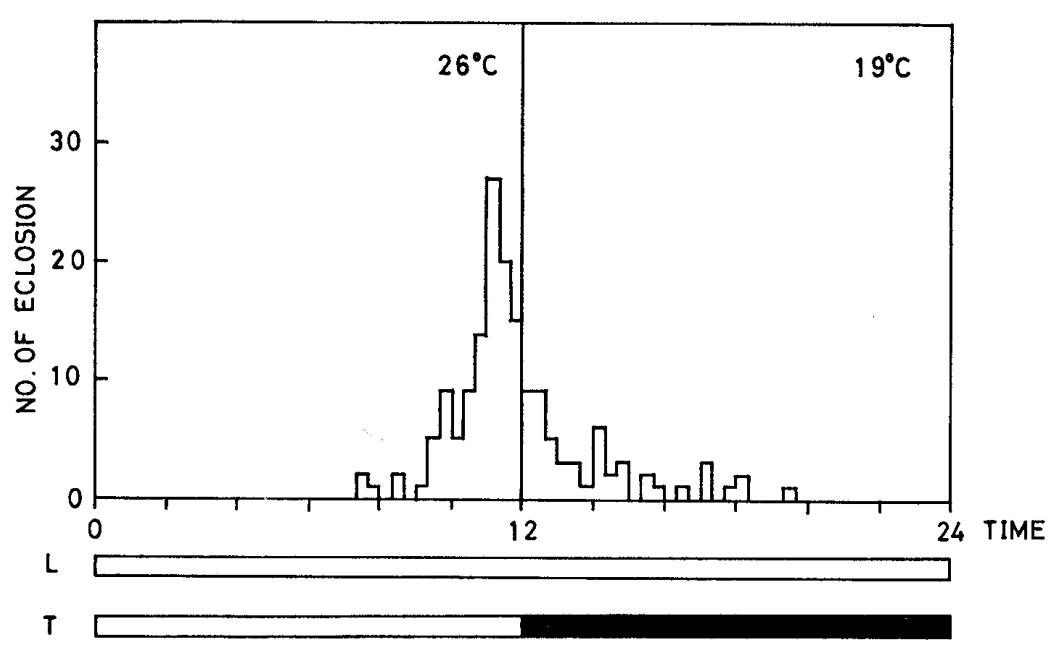

Fig. 3. Pattern of adult eclosion in $H$. cunea under a thermoperiod of $12 \mathrm{hr}$ at $26^{\circ} \mathrm{G}$ and $12 \mathrm{hr}$ at $19^{\circ} \mathrm{C}$ in constant light.

1 to 2 hours before the drop in temperature. At a constant temperature in continuous darkness, adult eclosion occurred randomly (Fig. 2-b and c). Another group of pupae were kept in continuous light under a thermoperiod of $12 \mathrm{hr}$ at $26^{\circ} \mathrm{C}$ and $12 \mathrm{hr}$ at 19 ${ }^{\circ} \mathrm{C}$. Here also, a definite peak of adult eclosion was observed about 1 hour before the drop in temperature (Fig. 3). Although some individuals emerged after the temperature drop, the eclosion pattern under these conditions was similar to that in continuous darkness. In the absence of photoperiodic cue the timing of adult eclosion is thus closely correlated with the change in temperature. A change in temperature seems therefore to be effective as a time cue.

\section{FREE RUNNING RHYTHM IN GONSTANT TEMPERATURE}

A number of pupae were subjected to a thermoperiod of $12 \mathrm{hr}$ at $26^{\circ} \mathrm{C}$ and $12 \mathrm{hr}$ at $19^{\circ} \mathrm{C}$ in continuous darkness from the day of pupation, and their eclosion pattern for 4 days was recorded under the same conditions (Fig. 4). Then the $12 \mathrm{hr}$ phase of $19^{\circ} \mathrm{C}$ was replaced by a $12 \mathrm{hr}$ of $26^{\circ} \mathrm{C}$, thus the pupae were kept at a constant temperature of $26^{\circ} \mathrm{C}$ in continuous darkness. As shown in Fig. 4, the first peak of eclosion after the abolishment of thermoperiod occurred about $24 \mathrm{hr}$ after the last peak in the thermoperiod. Second and third peaks of eclosion even more clearly appeared at approximately $24 \mathrm{hr}$ intervals. This result indicated that a change in temperature, as well as a change in light, act as a "phasing" factor in the endogenous circadian periodicity. However, temperature and light strimuli are not quite the same in their actions as the time cue. The peak of adult eclosion was observed about 1 hour after a light-off stimulus, while it occurred before the temperature-drop stimulus (Fig. 2a and 3). This strongly suggests the existence of a difference in the mode of action between these two kinds of stimuli: light-off and temperature drop.

\section{COMPARISON OF THE EFFEGTS OF LIGHT OFF AND TEMPERATURE DROP}

To analyse the interaction of these two time cues, four groups of pupae were sub- 


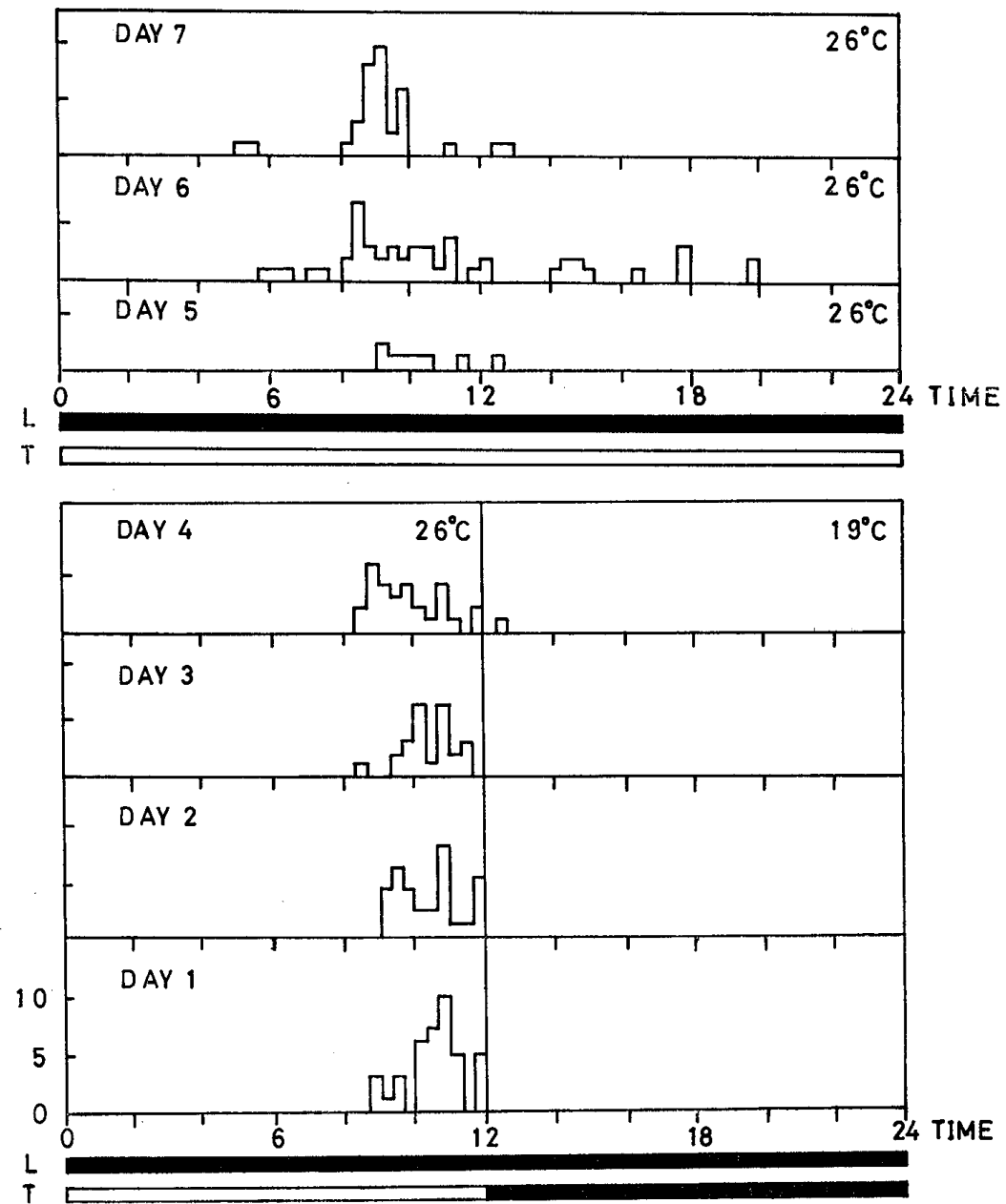

Fig. 4. Pattern of adult eclosion in $H$. cunea when kept in a thermoperiod of $12 \mathrm{hr}$ at $26^{\circ} \mathrm{C}$ and $12 \mathrm{hr}$ at $19^{\circ} \mathrm{C}$ in continuous darkness for four days and then placed under a free-running condition of constant temperature of $26^{\circ} \mathrm{G}$ and continuous darkness.

jected to combinations of photoperiod and thermoperiod with different phase relations. In the first and second groups, a photoperiod of $12 \mathrm{hr}$ of light and $12 \mathrm{hr}$ of darkness (12L12D) was combined with a thermoperiod of $12 \mathrm{hr}$ at $26^{\circ} \mathrm{C}$ and $12 \mathrm{hr}$ at $19^{\circ} \mathrm{C}$ in such a phase relation that the onset of low temperature period comes at the middle of the dark period (group 1) or of the light period (group 2) (Fig. 5a and b). In group 1 (Fig. 5a), in which the temperature drop came $6 \mathrm{hr}$ after the light-off, a definite peak of eclosion occurred about 1 hour after the light off, but elcosion lasted for more than 8 hours thereafter. This is considerably different from the results expected under similar photoperiodic conditions without change in temperature, where adult eclosion is concentrated within a few hours. Obviously, the drop in temperature following lightoff modified the pattern of adult eclosion.

The pattern of eclosion in this group seems to be attributed to the combined effects of the two time cues: the peak shortly after the light-off was induced by the lightoff and the eclosion lasting thereafter was probably due to the temperature drop.

In group 2 (Fig. 5b), where temperature drop occurred 6 hours before light-off, eclosion was observed for over more than 13 hours. Two major peaks seem to be pre- 


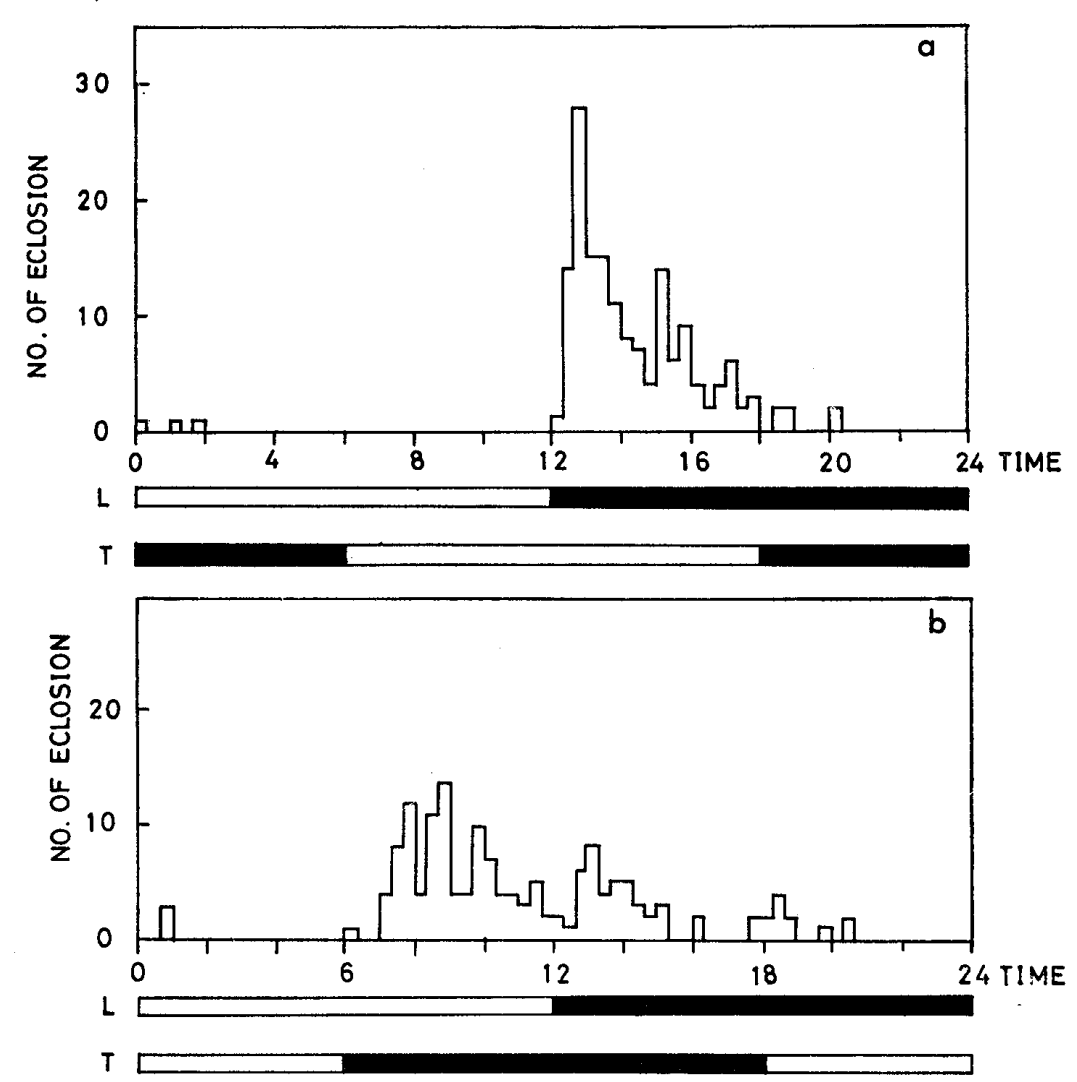

Fig. 5. Pattern of adult eclosion in H. cunea in a photoperiod of 12L12D combined with a thermoperiod of $12 \mathrm{hr}$ at $26^{\circ} \mathrm{C}$ and $12 \mathrm{hr}$ at $19^{\circ} \mathrm{C}$ in such a phase relation that the onset of low temperature period comes at the middle of dark period (a) or of the light period (b).

sent, however: one at about 3 hours before, and another at about 1 hours after light off.

In groups 3 and 4, two cycles of $6 \mathrm{hr}$-light and $6 \mathrm{hr}$-dark photoperiod were combined with a thermoperiod of $12 \mathrm{hr}$ at $26^{\circ} \mathrm{C}$ and $12 \mathrm{hr}$ of $19^{\circ} \mathrm{C}$, and the drop in temperature was synchronized with the onset of the dark phase (group 3) or the light phase (group 4) of the second cycle (Fig. 6). In group 3, a definite peak of eclosion was observed about 1 hour after light-off, synchronized with temperature drop. In group 4 (Fig. 6b), where the temperature drop applied simultaneously with the second light-on, eclosion was concentrated within the first dark period, and no eclosion occurred after the second light-off. Also, the presence of two peaks was suggested: a major one situated about 1 to 2 hours before light-on, i.e., before temperature drop, and a minor one about $1 \mathrm{hr}$ after the first light-off. These results clearly demonstrate that the light-off stimulus is not the only factor determining the time of eclosion, but the temperature drop stimulus also exerts a strong effect.

In group 2 and 3, the eclosion which was expected to occur in advance of temperature drop was never observed. These results were in contradiction to other groups of experiments where the temperature drop induced eclosion before it (Fig. 1c, 2a, 3). The presence of light at the time of expected eclosion cannot account for the event, because advanced eclosion occurred, whether it was light (Fig. 1c, 3) or dark (Fig. 2a), 

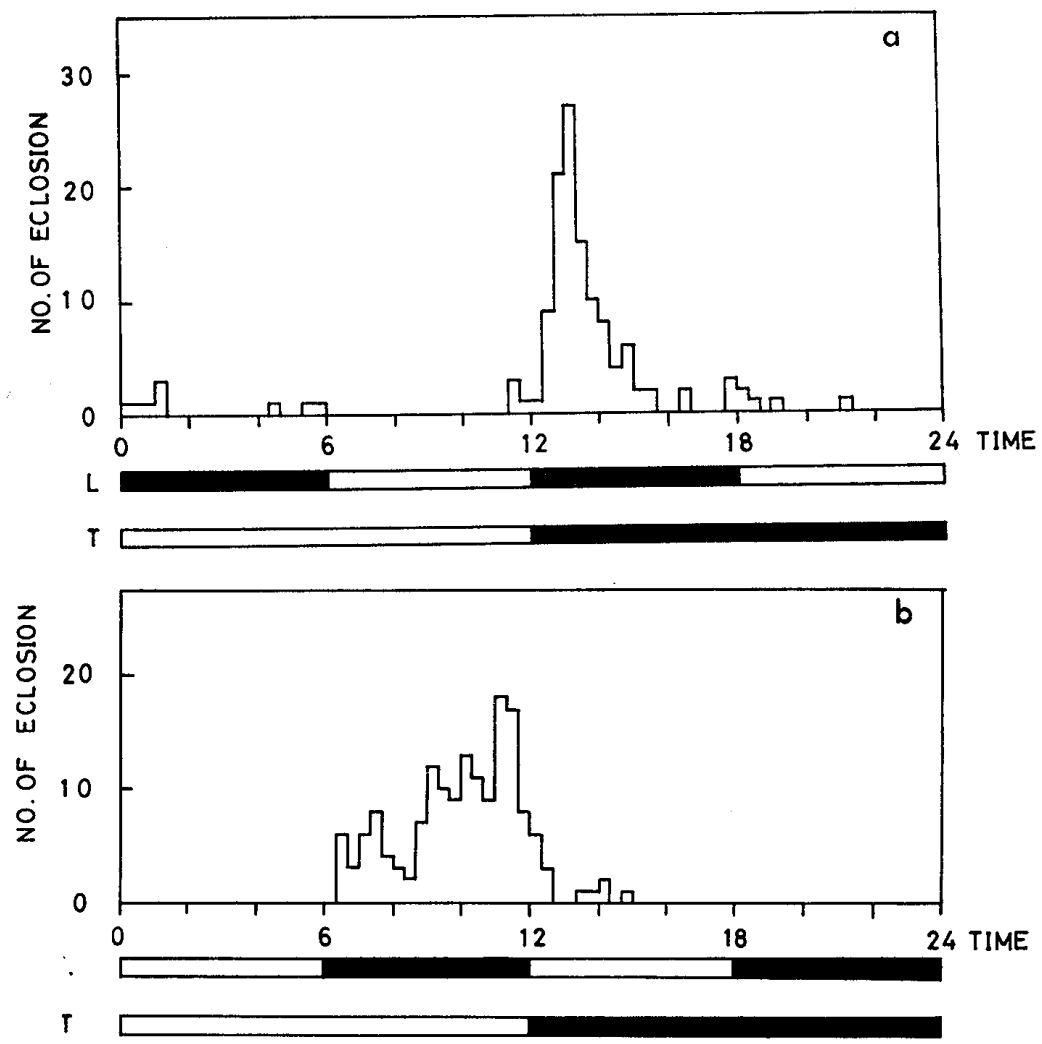

Fig. 6. Pattern of adult eclosion in $H$. cunea in a 6L6D photoperiod combined with a thermoperiod of $12 \mathrm{hr}$ at $26^{\circ} \mathrm{C}$ and $12 \mathrm{hr}$ at $19^{\circ} \mathrm{C}$ in such relation that drop in temperature synchronized with the onset of dark phase (a) or the light phase (b) of the second cycle.

just before temperature drop.

Further examination of the results, however, proved that eclosion occurred, as expected, before the temperature cue when the light period had lasted for $12 \mathrm{hr}$ prior to the temperature drop. Light period as short as $6 \mathrm{hr}$ preceeding the temperature cue may interfere with eclosion-inducing action of temperature drop.

\section{RELATIVE IMPORTANGE OF TEMPERATURE DROP AND LIGHT OFF AS A TIME GUE}

The experiments mentioned above were concerned with the interaction of the two cues in determining the eclosion rhythm. To examine the relative importance of light-off and temperature drop as a time cue, a group of pupae were subjected to a combination of a photoperiod of $12 \mathrm{hr}$ of light and $12 \mathrm{hr}$ of dark and a thermoperiod of $12 \mathrm{hr}$ at $26^{\circ} \mathrm{C}$ and $12 \mathrm{hr}$ at $19^{\circ} \mathrm{C}$. Light-off came at hour 0 and temperature-drop at hour 12 of the $24 \mathrm{hr}$ cycle. Since the two cues were spaced with $12 \mathrm{hr}$ 's interval, the animals were forced to make a choice of either as the more effective cue.

As shown in Fig. 7, a definite peak of eclosion occurred about 1 to 2 hours before temperature drop and not after light-off. The pattern of the eclosion under these conditions was almost similar to that under temperature cycles in constant dark (Fig. 2a) and constant light (Fig. 3). This result suggests that the stimulus of temperature change 


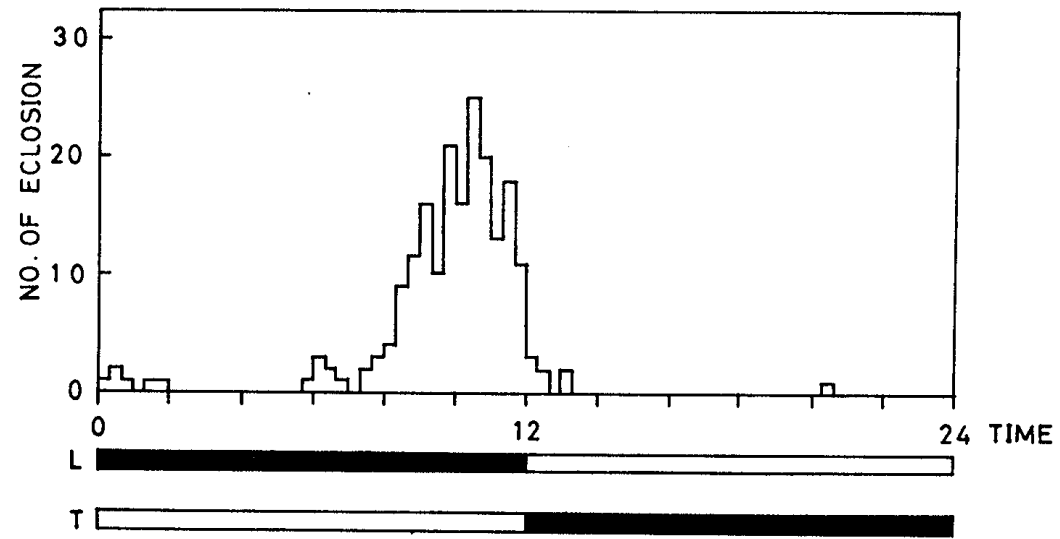

Fig. 7. Pattern of adult eclosion in $H$. cunea in a combination of a photoperiod of $12 \mathrm{~L} 12 \mathrm{D}$ and a thermoperiod of $12 \mathrm{hr}$ at $26^{\circ} \mathrm{C}$ and $12 \mathrm{hr}$ at $19^{\circ} \mathrm{C}$. The light-off came at the hour 0 and the temperature drop at the hour 12 of the $24 \mathrm{hr}$ cycle.

has a stronger effect as the time cue of adult eclosion in $H$. cunea than that of light-off, at least within the range of temperature tested in this work.

\section{DISCUSSION}

From the present experiments, it is confirmed that the drop in temperature has a strong effect on eclosion rhythm in $H$. cunea, and that it acts as a time cue, as shown in Drosophila (Pittendrigh, 1954) and in some other organisms (SWEeney and Hastings, 1960).

The studies on the interaction of light and temperature cycles have shown that light entrains more strongly than does temperature (PitTendrigh and Bruae, 1957, Pittendrigh, 1958). However, the present results do not conform to those of PitTENDRIGH and his co-workers. In their experiments, temperature was fluctuated within a range of $16^{\circ} \mathrm{C}$ and the change was made gradually. Under these conditions the temperature drop might be less effective as a time cue than light which was abruptly switched on or off. Temperature and light should be changed in the same way in order to compare their relative effect. There may be, however, a specific difference between the fruit fly and $H$. cunea.

In the present experiment where there was an abrupt change in temperature, the peak of eclosion occurred a few hours before the temperature drop, even when this was accompanied by light-on. This suggests that temperature drop is more effective as a time cue than light-off. The fact that eclosion occurs before the stimulus itself indicates that the temperature drop acts not as a"gating" factor as the light-off, but as an entraining factor.

As stated in a previous paper, eclosion of the overwintered generation was observed to occur more than two hours before dusk. It was suggested that the timing of eclosion in the overwintered generation is modified by the temperature drop in the afternoon. As shown in Fig. 1, when a light-off stimulus was accompanied by temperature drop, an earlier eclosion was usually induced. Although an abrupt temperature change rarely occurs in the field, a marked temperature drop in the afternoon will be an important factor in the timing of eclosion in the case of overwintered generation. 
The questions raised here are (1) why the temperature drop in the morning does not act as eclosion-inducing, and (2) whether or not the overwintered generation is essentially different from the summer generation, for it has passed a long period of diapause. These problems are now under experimental analysis.

\section{ACKNOWLEDGEMENTS}

The author expresses his sincere gratitude to Prof. Dr. T. HIDAKA of Laboratory of Biology, Tokyo University of Agriculture and Technology and Prof. Dr. S. MASAKI of Laboratory of Entomology, Faculty of Agriculture, Hirosaki University for their invaluable criticisms and reading manuscript and to $\mathrm{Mr}$. A. Кокиво of Institute of Forest Zoology, Faculty of Agriculture, University of Tokyo for his kind advices. Thanks are also due to members of Tokyo University Forest Experiment Station at Tanashi, Tokyo, for their helps throughout the experiments.

\section{REFERENGES}

Hrrar, Y. (1969) Biology of Hyphantria cunea DRURY (L.epidoptera : Arctiidae) in Japan. VIII. Experimental studies of the timing mechanism of adult eclosion. Appl. Ent. Zool. 2 : 100-110.

Pittendrigh, G. S. (1954) On temperature independence in the clock system controlling emergence time in Drosophila. Proc. Nat. Acad. Sci. L.S. 40 : 1018-1029.

Pittendrigh, C. S. (1958) Perspectives in the study of biological clocks. In Perspectives in Marine Biology, (ed. A. A. Buzzati-Traverso), University of California Press, Berkeley and Los Angeles, pp. 239-268.

Pittendrigh, G. S. and V. G. Bruge (1957) An oscillator model for biological clocks. In Rhythmic and Synthetic Process in Growth, (ed. Rudnick), Princeton University Press, Princeton, pp. 75-109.

SwEeney, B. M., and J. W. Hastings](1960) Effects of temperature upon diurnal rhythms. Cold Spring Harbor Symp. Quant. Biol. 25 : 87-102. 